\title{
Arqueologia na Região das Grandes Lagoas do Pantanal
}

José Luis dos Santos Peixoto*

As regiões do Chaco e Pantanal são consideradas áreas de grande complexidade étnica, expressa pela presença de diferentes grupos indígenas, mas que apresentam, também, assentamentos, subsistência e cultura material semelhantes entre si, dificultando assim a associação dos povos indígenas conhecidos historicamente com os povos pré-coloniais que ocuparam sítios arqueológicos caracaterizados como aterros.

As estratégias utilizadas pelos povos indígenas que estabeleceram seus assentamentos no Pantanal, seja em tempos históricos ou pré-históricos, estão diretamente relacionadas às variáveis culturais provocadas pela diversidade étnica e às variáveis ambientais provocadas pelos diferentes períodos hidrológicos e pela grande disponibilidade de recursos de fauna e flora.

Palavras-chave: Arqueologia do Pantanal; Aterros arqueológicos; Índios do Pantanal

The regions of Chaco and Pantanal are considered highly complex ethnic areas, with the presence of different indigenous groups. They present, however, similar settlements, subsistence and cultural material, which hampers the association of historically known indigenous peoples with pre-colonial peoples who occupied archeological sites characterized as embankments.

The strategies utilized by indigenous peoples who established their settlements in Pantanal,

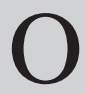
s estudos sistemáticos de Arqueologia no Pantanal iniciaram em 1990 e tem continuamente produzido informações sobre os seus primeiros habitantes. Estes estudos concentraramse na região das Grandes Lagoas do Pantanal (GLP), situada entre a planície de inundação da margem direita do rio Paraguai até o limite com o Planalto boliviano. Nesta paisagem há um conjunto de lagoas, individualizadas pelo nome de lagoas do Jacadigo, Negra, de Cáceres, do Castelo, Vermelha, Mandioré, Gaíva, Uberaba, Piranhas e Orion (FIG.1). As lagoas estão ligadas diretamente ao rio Paraguai através de canais fluviais e por transbordamento lateral da margem direita do rio no período de cheia.

Ao longo dos anos as pesquisas arqueológicas tiveram a preocupação de compreender como os povos indígenas utilizaram os recursos ambientais, as

* Professor Doutor do Curso de História (UFMS/CPAN/DHL), Bolsista do CNPq. jl.peixoto@terra.com.br 
whether in historic or prehistoric times, are closely related to the cultural variables triggered by the ethnic diversity and environmental variables provoked by different hydrological periods and by the large availability of fauna and flora resources

Keywords: Pantanal Archeology ; archeological embankments; Pantanal Indians

tecnologias disponíveis e a implantação dos assentamentos na paisagem. Também, foram produzidos vários trabalhos historiográficos baseados em fontes etnohistóricas sobre os grupos étnicos Xaray, Chané, Guató, Mbayá-Guaicurú, Payaguá e Toba, que possibilitou uma melhor compreensão das sociedades indígenas, sobretudo, em questões relacionadas às relações interétnicas, as áreas geográficas, os assentamentos, a subsistência e a cultura material. Estes estudos reuniram informações que contribuíram para a interpretação dos dados arqueológicos, numa perspectiva de utilizar as informações etnohistóricas como suposições e não como algo definitivo. Os usos de "modelos" etnográficos são de extrema relevância para o Pantanal, pois o rio Paraguai percorre de norte a sul, sendo uma importante via de dispersão e comunicação, tanto para etnias indígenas, quanto para os conquistadores europeus.

As informações sobre os povos indígenas mencionados acima possibilitam o conhecimento sobre os recursos naturais extraídos dos territórios sob o seu domínio. A exploração dos recursos pode diferenciar-se dependendo do grupo étnico, pois a sua subsistência e adaptabilidade ambiental estão condicionadas as estruturas socioeconômicas de cada grupo indígena. Evidentemente que dispor de um determinado local que assegure a sobrevivência é condição sine qua non para qualquer grupo humano, mas no caso do Chaco e Pantanal, parece não representar exclusividade sobre uma determinada paisagem. De acordo com Susnik (1982) os domínios de certos espaços não caracterizam domínio de territórios, mas locais exclusivos de exploração de recursos, que como consequiência do uso poderia levar a alianças ou a conflitos provocando guerras intertribais, conforme é sugerido por Branislava Susnik:

El espacio vital de los indígenas chaqueños constituyen sus cazaderos, algarrobales y pesqueros; el 'cazadero' es para ellos 'su tierra'; y los cazaderos tienen sus límites definidos por riachos, ríos, palmares y esteros; tales 'límites' implicaban un derecho exclusivo de explotación de los recursos. Cada parcialidad - banda de una tribu posee su cazadero subsistencial; no hay 'tierra tribal', de 
donde también la falta de una estructura sociopolítica tribal de los Chaqueños. Las inv'taciones interparciales se extienden con frecuencia a los 'permisos' de caza o recolección de algarrobo, una prática bastante común entre os Lengua - Maskoys sureños; las antiguas bandas de los Eyiguayegi - Mbayáes solían convivir temporalmente en lugares y épocas apropiadas para la gran caza abundante; los Angaité Maskoys llegaron al 'trueque' de permisos de caza. Por otra parte, la invasión violenta de otra banda en el cazadero ajeno podía provocar rencillas y agresiones interparciales, especialmente cuando la época de hambrunas, defendiendo cada banda sus propios recursos subsistenciales. Una invasión de otra tribu en el espacio vital de alguna parcialidad provodaba ya verdaderas guerras intertribales; el ejemplo de las guerras Toba y Enimagá - Cochaboth por el dominio del R. Confuso a fines del siglo XVIII testimonia lo dicho ${ }^{1}$. (grifo nosso)

As regiões do Chaco e Pantanal são consideradas áreas de grande complexidade étnica com presença de diferentes grupos indígenas, mas apresentam assentamentos, subsistência e cultura material semelhantes entre si, dificultando a associação dos povos indígenas conhecidos historicamente e os povos indígenas pré-coloniais que ocuparam os Aterros.

Por outro lado, os estudos realizados por Schmitz et alii ${ }^{2}$, Migliacio $^{3}$, Oliveira ${ }^{4}$ e Peixoto ${ }^{5}$ demonstram que a presença dos primeiros habitantes do Pantanal inicia-se antes da conquista européia. Os primeiros assentamentos a ser fixados na planície pantaneira datam de 5.500 anos A.P. e pertencentem a grupos de pescadores-coletores-caçadores. Até o momento não foi possível relacionar as informações arqueológicas referente à cultura material, os sepultamentos, a arqueofauna,

${ }^{1}$ SUSNIK, B. Los Aborigenes del Paraguay. T. IV. Cultura Material. Asunción: Museu Etnográfico "Andres Barbero", 1982, 237 p.

${ }^{2}$ SCHMITZ, P. I.; ROGGE, J. H.; ROSA, A. O.; BEBER, M. V. Aterros Indígenas no Pantanal do Mato Grosso do Sul. Pesquisas, n. 54, 1998, p. 1-271.

${ }^{3}$ MIGLIACIO, M. C. A Ocupação Pré-colonial do Pantanal de Cáceres, Mato Grosso: uma leitura preliminar. Dissertação de Mestrado. São Paulo: USP/MAE, 2000, 402 p.

${ }^{4}$ OLIVEIRA, J. E. Da Pré-história à História Indígena: (re)pensando a arqueologia e os povos canoeiros do Pantanal. 2002. 466 p. Tese (Doutorado em História) - Curso de pós-graduação em História da Faculdade de Filosofia e Ciências Humanas da Pontifícia Universidade Católica do Rio Grande do Sul, Porto Alegre, 2002.

${ }^{5}$ PEIXOTO, J. L. S. A Ocupação dos Povos Indígenas Pré-coloniais nos Grandes lagos do Pantanal Sul-mato-grossense. 2003. 262 p. Tese (Doutorado em História) - Curso de Pós-Graduação em História da Faculdade de Filosofia e Ciências Humanas da Pontifícia Universidade Católica do Rio Grande do Sul, Porto Alegre, 2003. 


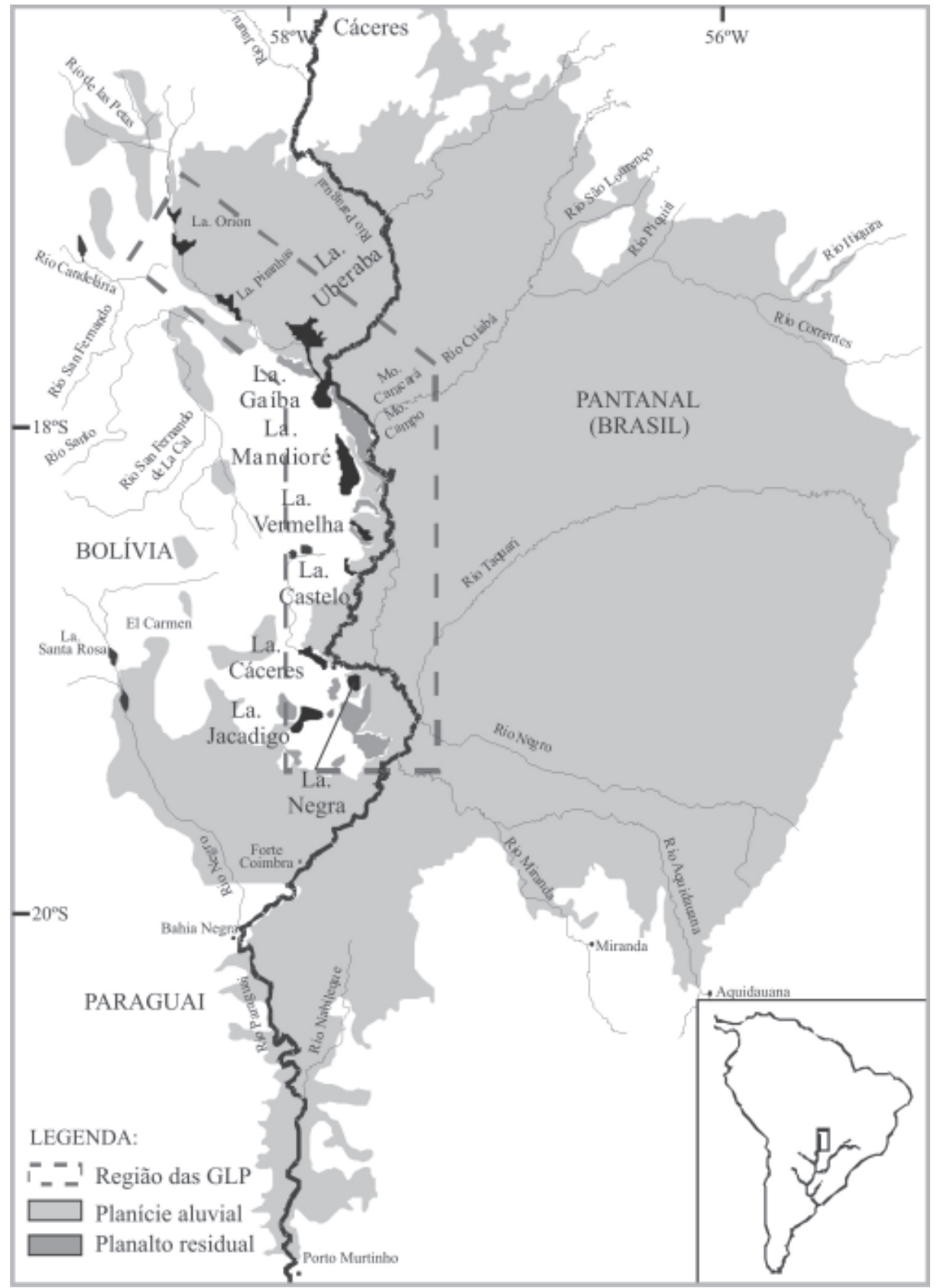

Figura 1. Mapa do Pantanal com destaque para a região das Grandes Lagoas do Pantanal (GLP). 
a estratégia de capitação dos recursos ambientais, os assentamentos e os limites temporais das sucessivas ocupações indígenas a qualquer grupo indígena conhecido historicamente. Este é um problema de difícil solução, pois muitas informações recuperadas pela Arqueologia são elementos comuns entre os vários grupos de pescadores-coletores-caçadores do Pantanal.

A estratégia de implantação dos assentamentos pré-coloniais na paisagem parece ser um elemento comum entre os povos indígenas, que ocuparam a planície pantaneira. A fixação dos assentamentos é, preferencialmente, ao redor das grandes lagoas e ao longo de um intricado sistema de canais fluviais, onde o deslocamento é facilitado pelo uso da canoa e pelo conhecimento detalhado da hidrografia local, pois facilmente o navegante pode confundir-se entre as várias opções de canais fluviais, que para os grupos indígenas são caminhos que servem para seus deslocamentos. Evidentemente que um intricado sistema de canais torna-se um fator de proteção contra invasões de grupos externos, seja por grupos indígenas rivais ou pelos portugueses e espanhóis.

Os assentamentos implantados dentro da planície de inundação são identificados em vários locais nas Américas, mas com denominações distintas. No Brasil denomina-se de Sambaqui para os localizados na planície costeira; no Uruguai e sul do Brasil denomina-se de Cerritos para os localizados na planície costeira; na Amazônia Boliviana denomina-se de Loma para a região de Llanos de Moxos; na Argentina denomina-se de Conchales; no Paraguai denomina-se de Montículos; no Pantanal (Brasil) denomina-se de Aterros; e genericamente conhecidos como Mounds em várias partes do mundo, tais como: ilha de Marajó (Brasil), rio Orinoco (Venezuela), rio Mississipi (EUA) entre outros.

Alguns estudos sugerem que os povos indígenas que ocuparam as diferentes planícies de inundação parecem ter uma organização social complexa. $\mathrm{Mazz}^{6} \mathrm{e}$ Lima e Mazz ${ }^{7}$ sugerem que os Cerritos poderiam ser ocupados por uma socieda-

\footnotetext{
${ }^{6}$ MAZZ, J. L., BLANCO, S. P. Distribución espacial de estruturas monticulares em la cuenca de la Laguna Negra. In: SIMPÓSIO INTERNACIONAL DE ARQUEOLOGIA DE LAS TIERRAS BAJAS. Montevideo, 1996. Anais... Montevideo: Ministério de Educación, 2000, p. 49-58.

${ }^{7}$ LIMA, T. A., MAZZ, J. L. La emergencia de complejidad entre los cazadores recolectores de la costa Atlântica Meridional Sudamericana. Revista de Arqueologia Americana, n. 17/19, 2000, p. 129175 .
} 
de com características que apontam para o sedentarismo, a desigualdade social, o trabalho especializado, a trocas a longa distância, a arte elaborada, os sepultamentos diferenciados, entre outras. Erickson ${ }^{8}$ sugere para região de Llanos de Moxos vários tipos de Lomas, que são classificados por tamanho, forma e complexidade e considerados construções artificiais. Provavelmente, os Lomas não foram usadas apenas para uma única função, mas multifuncionais, tais como: habitação, cemitério, rituais, campos de cultivo, lugares de caça, limites políticos e territoriais ${ }^{9}$. Os Monds presentes na ilha de Marajó (Brasil) são considerados sistemas organizados de assentamentos que se relacionam entre si e possuem um padrão de distribuição regional de sítios, havendo diferentes funções com usos permanentes, sazonais e periódicos ${ }^{10}$. Para o vale do Mississipi e litoral brasileiro os Mounds e os Sambaqui, respectivamente, são compostos pela acumulação de múltiplos eventos deposicionais efetuados por diversas gerações e são interpretados como um complexo sistema social ${ }^{11}$.

No Pantanal estudos realizados por Schmitz et alii ${ }^{12}$ e Schmitz ${ }^{13}$ sobre os Aterros do Pantanal afirmam que os responsáveis pelo surgimento dos Aterros são povos indígenas pertencentes a Tradição Pantanal constituídos por socieda-

${ }^{8}$ ERICKSON, C. L. Lomas de ocupación em los Llanos de Moxos, Bolívia. In: SIMPOSIO INTERNACIONAL DE ARQUEOLOGIA DE LAS TIERRAS BAJAS, Montevideo, 1996, Anais... Montevideo: Ministerio de Educación, 2000, p. 195-206.

${ }^{9}$ Idem, p. 210-211.

${ }^{10}$ ROOSEVELT, A. C. Moundbuilders of the Amazon: Geophysical Archaeological on Marajo Island, Brazil. New York: Academic Press, 1991. Cap. The Marajoara Chiefdom, p. 39-30; ROOSEVELT, A. C. Moundbuilding societies of the Amazon and Orinoco. In: SIMPOSIO INTERNACIONAL DE ARQUEOLOGIA DE LAS TIERRAS BAJAS. Montevideo, 1996. Anais.... Montevideo: Ministério de Educación, 2000, p 143.

${ }^{11}$ HAMILTON, F. E. Southeastern archaic mounds: examples of elaboration in a temporally environment. Journal of Anthropological Archaeology, n. 18, 1999, p. 344-355; HAMILTON, S. K., SIPPEL, S. J., MELACK, J. M. Inundation patterns in the Pantanal wetland of South America determined from passive microwave remote sensing. Arch. Hydrobiol., 137(1), p. 1-23, 1996; FISH, S. K., BLASIS, P., GASPAR, M. D., FISH, P. R. Eventos incrementais na construção de sambaquis, litoral sul do estado de Santa Catarina. Revista do Museu de Arqueologia e Etbologia, n. 10, 2000, p. 69-88.

${ }^{12}$ SCHMITZ, P. I. et alii. Op. cit.

${ }^{13}$ SCHMITZ, P. I. Os pescadores-coletores-caçadores do Pantanal de Mato Grosso do Sul - Região de Corumbá. In: TENÓRIO, M. C. Pré-história da Terra Brasilis. Rio de Janeiro: Ed.UFRJ, 1999, p. $149-158$. 
des forrageiras de pescadores-coletores-caçadores. Os seus assentamentos estão distribuídos na planície de inundação entre rios, lagoas e canais fluviais, onde se encontra abundância de flora e fauna. De acordo com Schmitz et alii. ${ }^{14}$ a sazonalidade dos recursos ambiental responde em parte pelos deslocamentos estacionais dos grupos indígenas, que produzem dois tipos de assentamentos: assentamentos centrais e sazonais. Os centrais estão estabelecidos juntos às grandes lagoas e ao longo de diques fluviais, possuem características mais estáveis, grande densidade de material cerâmico, presença de sepultamento primário, camadas arqueológicas espessas (superior a $1 \mathrm{~m}$ ), abundância de remanescentes faunísticos (peixes, anfíbios, répteis, aves, mamíferos e malacológicos), maior tamanho e parece ocorrer espaço privilegiado de ocupação. Os assentamentos sazonais possuem escassos remanescentes faunísticos e material cerâmico, sem sepultamentos, são extensos e pouco densos e estão localizados distantes dos principais cursos d' água. De acordo com os mesmos autores a continuidade dos atributos na confecção do material cerâmico e na longa duração dos assentamentos centrais parece ser um bom indicador de permanência por várias gerações no mesmo Aterro. Migliacio ${ }^{15}$ em estudos realizados na borda norte do Pantanal sugere que os Aterros estão distribuídos na paisagem em conjuntos articulados e possuem forma circular ou elíptica que parecem ser construções artificiais. A referida autora reconhece que padrões diversificados de sepultamento presentes em vários Aterros apontam para complexidade social. Oliveira ${ }^{16}$ sugere que os Aterros do Pantanal têm alto significado social e parece indicar local para cerimônias e rituais, fortalecimento da sua identidade étnica e estabelece territorialidade ou área de domínio exclusivo para pesca, coleta e caça.

Os vários estudos em desenvolvimento sugerem que as sociedades instaladas em planície de inundação possuem um sistema organizado de assentamentos, que se relacionam entre si através de um padrão e distribuição regionais de sítios, os quais desempenham diferentes funções e atividades, com usos permanentes, sazonais e periódicos, refletindo certo grau de sedentarismo e desigualdades sociais. Entretanto, os pesquisadores que realizam estudos no Pantanal reconhecem

\footnotetext{
${ }^{14}$ Idem, p. 237-238.

${ }^{15}$ MigliaCiO, M. C. Op. Cit.

${ }^{16}$ OLIVEIRA, J. E. Op. Cit.
} 
que os modelos que sugerem uma complexidade social para os grupos pescadores-coletores-caçadores que ocuparam os Aterros são prematuros.

As estratégias utilizadas por povos indígenas que estabeleceram seus assentamentos no Pantanal, seja em tempos históricos ou pré-históricos, estão diretamente relacionadas às variáveis culturais provocadas pela imensa diversidade étnica e variáveis ambientais provocadas pelos diferentes períodos hidrológicos e disponibilidade de recursos de fauna e flora.

As planícies de inundações apresentam, periodicamente, uma inundação pelo transbordamento lateral dos rios e lagos e/ou por precipitação direta ou por lençol de água subterrânea, que são responsáveis pela manutenção da produtividade e interação entre o rio e a planície. No Pantanal as condições geomorfológicas e hidrológicas produzem pulsos de inundações, que abrangem aspectos previsíveis de longa duração e proporcionam aos organismos desenvolver adaptações e estratégias eficientes na utilização de habitat e uso dos recursos dentro de uma zona de transição que se alterna entre ambiente aquático e terrestre ${ }^{17}$. A variabilidade de estruturas físicas em combinação com o pulso de inundação resulta numa grande diversidade de habitat, favorecendo uma ampla diversidade de plantas e animais aquáticos e terrestres. Apesar do considerável estresse provocado pelas mudanças de fase terrestre e aquática. É importante salientar que a fertilidade depende diretamente da amplitude, freqüência e previsibilidade da ocorrência dos pulsos de inundação ${ }^{18}$ e que necessariamente reflete num maior ou menor estoque de recursos disponíveis aos povos indígenas.

Os níveis hidrológicos de inundação (cotas) numa planície são elementos importantes para a compreensão da ocupação humana em períodos atuais e pretéritos, sobretudo no caso do Pantanal. Portanto, é conveniente realizar uma análise mais detalhada dos ciclos de cheia e seca para que possamos refletir sobre o estabelecimento de assentamentos numa planície de inundação. No caso do Pantanal, temos uma excelente contribuição dos dados diários, proveniente da estação hidrométrica do

${ }^{17}$ JUNK, W. J., BAYLEY, P. B., SPARKS, R. E. The flood pulse concept in river-floodplain systems. Can. Spec. Publ. Fish. Aquat. Sci., 1989, p. 110-127; JUNK, W. J., SILVA, C. J. O conceito de pulso de inundação e suas implicações para o Pantanal de Mato Grosso. In: II SIMPÓSIO SOBRE RECURSOS NATURAIS E SÓCIO-ECONÔMICOS DO PANTANAL, 2 , Corumbá, 1996. Anais... Brasília: Embrapa, 1999, p. 17-28.

${ }^{18}$ JUNK, W. J., BAYLEY, P. B., SPARKS, R. E. Idem, p. 118. 
$6^{\circ}$ Distrito Naval da Marinha ${ }^{19}$, sobre as variações das cotas anuais máximas e mínimas do rio Paraguai entre 1900 e 2001. Em 1988 foi registrada a cota de maior altitude com 6,64 m e em 1964 a cota com menor altitude com 0,61 m, sendo que a cota de aproximadamente $3,5 \mathrm{~m}$ é referida por Brasil ${ }^{20}$ como estágio de transbordamento pela margem esquerda do rio Paraguai. As seqüências de anos de maiores cheias, alternando-se com outros de menores cheias, são denominados de ciclos plurianuais de cheias e ciclos plurianuais de secas ${ }^{21}$. De acordo com Galdino e Clarke 22 a média das cotas diárias entre os anos de 1900 e 1994 foi de 2,66 m e as cheias consideradas de grande amplitude tiveram cotas iguais ou superiores a $5,50 \mathrm{~m}$ e as de excepcional amplitude iguais ou superiores a 6,00 m. Associado aos níveis de inundação está o índice de retração da área inundada, que corresponde a um conjunto de períodos hidrológicos para o Pantanal em função da área inundada mensal entre os anos de 1991 e 200123. Dentro desse período, há alternância de seca (ano de 1994) e cheia excepcional (ano de 1995) "que a retração da área inundada anual variou de $45 \%$ em 1992 a 89 \% em 1999”24. O índice de retração da área inundada demonstra que a área navegável, por povos canoeiros, se reduz drasticamente, mesmo em períodos anuais de cheia de grande amplitude, limitando os seus deslocamentos na maior parte do ano, num território imediatamente adjacente ao rio Paraguai, sobretudo, na região das GLP. Outro fator importante que causam impactos negativos é o estresse hídrico, tanto em

\footnotetext{
${ }^{19}$ A régua linimétrica está instalada no $6^{\circ}$ Distrito Naval da Marinha Brasileira (Ladário/MS), nas coordenadas $19^{\circ} 02^{\prime}$ S e $57^{\circ} 33^{\prime}$ W e o seu zero encontra-se na altitude de $82,15 \mathrm{~m}$ (Brasil, 1979b).

${ }^{20}$ BRASIL. Ministério do Interior. Departamento Nacional de Obras de Saneamento. Estudos Hidrológicos da Bacia do Alto Paraguai. Rio de Janeiro: Departamento Nacional de Obras de Saneamento, 1974. v. 1 (Relatório Técnico).

${ }^{21}$ CADAVID GARCIA, E. A. Índices técnico-econômicos da região do Pantanal Mato-grossense. Corumbá: Embrapa-Uepae, 1981. 81 p. (Circular Técnica, 7).

${ }^{22}$ GALDINO, S., CLARKE, R. T. Levantamento e estatística descritiva dos níveis hidrométricos do rio Paraguai em Ladário, MS - Pantanal. Corumbá: Embrapa-CPAP, 1995. 72 p. (Embrapa-CPAP, Documentos, 14); GALDINO, S., CLARKE, R. T. Probabilidade de ocorrência de cheia no rio Paraguai em Ladário, MS - Pantanal. Período 1900-1994. Corumbá: Embrapa-CPAP, 1997. 58 P. (Embrapa-CPAP, Circular Técnica, 23).

${ }^{23}$ CATElla, A. C. A pesca no Pantanal de Mato Grosso do Sul, Brasil: descrição, nível de exploração e manejo (1994-1999). Manaus. 350 p. Tese (Pós-graduação em Biologia Tropical e Recursos Naturais). Universidade do Amazonas/Instituto Nacional de Pesquisa da Amazônia, 2001, p. 17-31.

${ }^{24}$ Idem, p. 36.
} 
ciclo plurianual de cheias pelo excesso de água, quanto em ciclo plurianual de secas por falta de água.

Os estudos realizados por Peixoto ${ }^{25}$ num conjunto de sítios, localizados na região das lagoas do Castelo e Vermelha, verificou que há uma relação direta entre as cotas dos sítios e os níveis hidrológicos do rio Paraguai. Na maioria dos períodos dos períodos de cheia os sítios se elevam acima da superfície da água. Entretanto em cheias excepcionais com cotas acima de $6 \mathrm{~m}$, apenas alguns sítios se sobressaem ao nível das águas com possibilidade de uso. Enquanto que a maioria dos Aterros é necessário seu abandono.

Por outro lado, a fixação do homem dentro da planície de inundação do Pantanal é favorecida pela previsibilidade do regime hidrológico, que possibilita planejar e desenvolver estratégias eficientes na instalação dos seus assentamentos e na busca dos recursos ambientais para sua subsistência. A sua mobilidade está diretamente relacionada aos rios, aos canais fluviais e a superfície da água atingida na planície, que proporcionam maior ou menor deslocamento, dependendo da amplitude das inundações. Em tempos de seca há um reduzido número de canais fluviais disponíveis para deslocamento em canoas, enquanto que, em tempos de cheia, há uma maior disponibilidade de canais e terrenos inundados. A distribuição espacial dos sítios indica que os assentamentos são preferencialmente instalados numa superfície naturalmente mais elevada do terreno, as margens de lagoas e canais fluviais e eventualmente próximos aos rios, possibilitando o acesso a diferentes ambientes e a vários pontos do território. Os movimentos migratórios podem estar relacionados com mudanças ambientais a curto prazo relacionado a ciclos plurianuais de cheia e seca e a longo prazo relacionado a mudanças no regime hidrológico, climatológico entre outros. Os movimentos migratórios podem estar relacionados com a busca de alimentos, a consolidação de território, contatos interétnicos e consolidação de lideranças. Estes movimentos migratórios podem ser verificados no tempo da conquista espanhola e lusa e poderiam, em tempos pré-coloniais, sem a pressão colonialista européia, ser os responsáveis por disseminar a manufatura da

\footnotetext{
${ }^{25}$ PEIXOTO, J. L. S. Relação entre os Aterros e níveis hidrológicos do rio Paraguai, Pantanal (MS). In: CONGRESSO DA SOCIEDADE BRASILEIRA DE ARQUEOLOGIA, 13, 2005. Campo Grande, MS, Anais... Campo Grande: Ed. Oeste, 2005. 1 CD-ROM.
} 
cerâmica, a confecção de instrumentos líticos e a construção de assentamentos. Outro ponto importante são as estratégias de implantação no terreno dos assentamentos, pois deveria ser levado em consideração a prevenção das grandes cheias e secas, direção das correntes de água e pontos estratégicos na busca de alimentos.

No Pantanal parece ser possível estabelecer uma hierarquia dos assentamentos a partir da correlação dos níveis de inundação do rio Paraguai e da área, da altura e da estratigrafia correspondente a cada assentamento. Desta maneira, Peixoto ${ }^{26}$ determinou a existência de assentamentos de ocupação anual, plurianual e sazonal. O uso do assentamento Anual está condicionado às cheias do rio Paraguai com cotas abaixo de 5,50 m. O uso do assentamento Plurianual é contínuo, seu tamanho obedece a um crescimento constante no plano horizontal e há uma estabilidade no seu crescimento no plano vertical, quando a sua superfície está acima do nível das cheias de grande amplitude. O Assentamento Sazonal está diretamente relacionado com captação de recursos próximos ou distantes dos assentamentos dependendo de sua função. Ao redor das grandes lagoas existem sítios de gravuras rupestres com um conjunto de símbolos, que articulados entre si, parecem estabelecer uma identidade étnica para um conjunto de lagoas. As gravuras, possivelmente, são contemporâneas ao estabelecimento dos grupos indígenas que ocuparam os Aterros, sendo estes os possíveis responsáveis pelos grafismos.

\section{Conclusão}

Os vários assentamentos distribuídos na planície de inundação parecem indicar um complexo sistema de assentamento, que são ocupados ora por grupos préceramista sotoposto por ceramistas ou ora por assentamentos, exclusivamente, ceramistas ou pré-ceramistas. Estabelecer hierarquia social entre os assentamentos é bastante tentador, mas até o momento não há dados que possibilite está discussão. A estratégia mais adequada ser seguida é realizar escavações amplas com cronologia bastante controlada nos diferentes tipos de Aterros. De acordo com as informações etno-históricas é possível inferir que, as alianças e o intercâmbio de

\footnotetext{
${ }^{26}$ Idem.
} 
informação social, política e ambiental são as bases de sustentação da organização das sociedades entre o séc. XVI e XIX e parte desse comportamento poderia estar presente entre os pescadores-coletores-caçadores do Pantanal. Parece certo que o acesso e domínio dos espaços vitais dentro do Pantanal, sobretudo, em período plurianual de cheia ou seca poderiam ter contribuído para aumentar o status político de um determinado grupo étnico, possibilitando o surgimento de lideres. As evidências arqueológicas para os grupos ceramistas estabelecidos, principalmente, na região das GLP, demonstram que há concentrações demográficas, sedentarismo parcial, reduzido espaço para fixação de assentamentos em razão dos ciclos de cheia e seca, domínio territorial através da distribuição dos Aterros e sítios de arte rupestre, sepultamentos diferenciados (primário e secundário) e manufatura especializada na confecção de materiais cerâmicos e diversificação na confecção de objetos de adorno. Estas evidências são elementos que associado a um ambiente com alta previsibilidade e produtividade de recursos ambientais proporcionam uma base alimentar estável para a subsistência, diminuindo a mobilidade do assentamento e favorecendo concentrações de grupos humanos.

No caso do Pantanal diferentes sociedades respondem a modos semelhantes de adaptações ambientais, em que a construção de estruturas de terra e o uso da canoa parecem ser condições sine qua non para estabelecimento dos povos indígenas a partir do Holoceno Tardio. A concentração de Aterros e a presença de sítios com gravuras rupestres junto às lagoas e afluentes do rio Paraguai indicam que esses locais são vitais para os povos indígenas pré-colonial e os conhecidos etnograficamente.

Os povos responsáveis pelos Aterros são especialistas em planície de inundação num intricado sistema de canais e lagoas, no qual a estratégia de ocupação do espaço é semelhante entre si, pois estão diante das mesmas pressões ambientais. Os movimentos migratórios podem estar relacionados com mudanças ambientais em curto prazo (ciclos plurianuais de cheia e seca) e longo prazo (mudanças no regime hidrológico, climatológico entre outros). Estes movimentos podem ser verificados no tempo da conquista espanhola e lusa e poderiam em tempos pretéritos, sem a pressão colonialista européia, ser os responsáveis pela difusão da manufatura da cerâmica, a confecção de instrumentos líticos, construção de canoas monóxila e Aterros entre os vários grupos étnicos. 
A região das GLP proporcionou o desenvolvimento de povos pescadorescoletores-caçadores, que estabeleceram unidades de domínio ou espaços vitais ao redor de uma ou um conjunto de lagoas em que as distribuições dos assentamentos não ocorrem de modo aleatório. A estratégia de ocupação dos espaços vitais parece estar diretamente relacionada com diferentes categorias de assentamentos.

A alta concentração de assentamentos nas margens das grandes lagoas, canais fluviais e foz de afluentes do rio Paraguai, juntamente com sítios de gravuras rupestres, poderiam representar identidade étnica, marcadores territoriais e/ou locais de rituais, área de caça, área de coleta e área de pesca, contribuindo para uma efetiva interação regional e social. Estes são requisitos que asseguram o controle de áreas de grande produtividade, sobretudo, em períodos de estresse hídricos (excesso ou falta de água) garantindo acesso aos recursos. A estratégia de ocupação do território seria através da instalação de assentamentos de duração plurianual, anual e sazonal. Os assentamentos plurianuais poderiam comportasse como estruturas de ocupação permanente mesmo em períodos de cheia excepcional e o tamanho do território está diretamente relacionado com o número de assentamento plurianual e anual coabitado e articulado com assentamentos sazonais e locais com gravuras rupestres distribuídos na paisagem. A cronologia dos Aterros indica que foram construídos de forma gradual e continua durante longos períodos e à medida que os assentamentos se consolidam os espaços vitais se concretizam.

Considerando o sistema de assentamento acima e associado a minha convivência entre os anos de 1995 e 2009 com a comunidade estabelecida sobre os sítios ora estudado é possível deduzir que durante o período de seca as famílias estão mais dispersa e isoladas ocupando os assentamentos anuais e os seus deslocamentos se restringem próximos aos assentamentos. Em períodos de cheias normais os assentamentos anuais continuariam ocupados, enquanto que os assentamentos plurianuais seriam locais de moradia permanente de uma determinada família e serviriam em ciclos anuais de cheia como locais de encontro para trocas de informações tecnológicas e mercadorias, reforço para coesão dos grupos familiares, manutenção da identidade étnica, rituais, sepultamentos, defesa do território entre outros. Os assentamentos sazonais seriam utilizados como locais provisórios para caça, para coleta e para pesca que conseqüentemente delimitariam o território de subsistência. Em tempos de águas altas as famílias tenderiam a concentrar-se nos assentamentos 
plurianuais e manteriam maior contato entre os assentamentos. A sua mobilidade aumentaria atingindo locais distantes e de difícil acesso que poderiam ser instalados assentamentos sazonais. Nos períodos de cheias excepcionais os assentamentos plurianuais se tornariam locais com alta concentração populacional, pois os demais assentamentos estariam submersos e, possivelmente, os residentes permanentes poderiam adquirir maior status perante o grupo. É possível afirmar que as cheias no Pantanal não provocam dispersão dos povos indígenas, ao contrário provocam maior concentração de indivíduos e possibilitam ampliar a busca de recursos em locais mais distantes, o que possibilita uma maior comunicação inter-regional e, assim, o estabelecimento de uma população com características sedentárias.

\section{Agradecimento}

O autor agradece o apoio financeiro da Fundação de Apoio ao Desenvolvimento do Ensino, Ciência e Tecnologia do Estado do Mato grosso do Sul (Fundect), Conselho Nacional de Desenvolvimento Científico e Tecnológico (CNPq) e a Universidade Federal do Mato Grosso do Sul (UFMS). 